\title{
A Case Study on Procedure Standardization of Heat Exchanger Retubing in KSA Oil and Gas Industries
}

\author{
Mohamed Fayas Saffiudeen", Fasil T. Mohammed, Abdullah Syed
}

Lecturer Department of Mechanical Skills, Jubail Technical Institute, Royal Commission of Jubail, Jubail Industrial city-31961, Jubail-Kingdom of Saudi Arabia

DOI: $10.36348 /$ sjet.2020.v05i02.004

| Received: 08.02.2020 | Accepted: 15.02.2020 | Published: 19.02.2020

*Corresponding author: Mr. Mohamed Fayas Saffiudeen

\section{Abstract}

Plant shutdown also known as "turnarounds", is one of the most critical period in the oil gas refineries in the Kingdom of Saudi Arabia. Shutdowns have the ability to affect the plant's financial future and commitments either in positive or negative way. A heat exchanger is crucial and important equipment in the oil gas refineries used for various processes and heat transfers. It also affects the duration of plant turnaround. When the operation of the plant starts the after turnaround, a failed heat exchanger within short duration of normal plant operation even though warranty of contractor exists, can create major loss in terms of money due to reduced downtime or production loss. Heat exchangers are subjected to different repairs including partial or full retubing by various methods or by simple plugging. Heat exchanger repair during the turnaround helps to reduce the down time loss (repair) of heat exchanger and will ensure the integrity for smooth running of plant. After studying the retubing of more than 75 heat exchangers, standardized procedure was incorporated to satisfy all the standard codes like ASME, TEMA, SAES, SES, NBIC and all the end users like Aramco, Sabic \& its affiliates.

Keywords: Shell \& heat exchanger maintenance, heat exchanger retubing, tubesheet cutting, tube expansion.

Copyright @ 2020: This is an open-access article distributed under the terms of the Creative Commons Attribution license which permits unrestricted use, distribution, and reproduction in any medium for non-commercial use (NonCommercial, or CC-BY-NC) provided the original author and source are credited.

\section{INTRODUCTION}

In oil gas field heat exchanger playing a vital role during the turnaround. They are used transfer the heat by inlet/outlet nozzles without mixing in different manufacturing processes and help to function the plant more efficiently with profit. In many industries, the heat loss is not utilized properly and it was wasted. Because of this, heat exchangers were created to arrest and reuse heat that would otherwise it would be lost to the environment. A heat exchanger is a device built for efficient heat transfer from one medium to another in order to carry and process energy [1]. Another crucial factor is safety during the repair and reinstallation. It is essential to confirm that heat exchangers must remain in good working condition at always. Systematic periodic maintenance, infrequent repair and retubing services during turnaround, cleaning of service deposits.

Shell and tube heat exchangers are commonly found in all the Saudi Aramco Plants, SABIC its affiliates plants in Kingdom of Saudi Arabia. When the tubes leak, efficiency of the shell is reduced. Tube heat exchangers then are restored through tubes plugging by tapered plug temporarily. When the number of tubes plugged or the impact of plugging decreases the efficiency of the heat exchanger, retubing needs to be done. Replacing the complete heat exchanger is expensive also, it requires preplanning. On the other hand, retubing is a cost effective option to increase the efficiency without replacing heat exchanger

\section{LITERATURE REVIEW}

After reviewing the Literature, it can be concluded that only limited work has been done in the field of Retubing of heat exchanger.B.I. Master et al. in 2006 found that more than $30 \%$ heat exchangers are used of shell and tube type. Shell and tube heat exchangers can be custom designed by considering its operability, maintainability, flexibility and safety. This makes it very robust and serves major reason to be used widely in industries [2] Yokell discussed some practical aspects of the expanded and welded-andexpanded tube-to-tubesheet joints and reviewed elasticplastic tube expanding theory [3]. Pramod S. Purandare et al. carried out experimental analysis to study the heat transfer phenomenon in conical coil heat exchanger with cone angle 90 degree [4]. Bouzid and Kazeminia conducted an analytical study to investigate the effect 
of reverse yielding on the contact pressure of hydraulically expanded tube-to-tubesheet joints [5]. Gajanan P Nagre 2016 studied the factors affecting the performance of shell and tube heat exchanger. The research focused on the design of small shell and tube heat exchanger with counter flow arrangement. The parameters of the thermal analysis considered such as baffle inclination, baffle spacing, flow rates of fluids, tube diameter by using CFD [6]. Merah et al. measured the tube-to-tubesheet joint strength in terms of residual contact pressure between the tube's outer surface and the tubesheet whole surfaces. The joint integrity is affected by several design parameters, including the type of material and the initial radial clearance [7].

In this paper, full retubing is carried out by two methods. First method is by tube sheet cutting method along with bundle pulling and second method by without cutting the tube sheet. Depending upon the enduser application, duration requirements any one of the method will be selected. If an end user want to conduct thickness study and inspecting the internals of heat exchanger like baffles, tie rods, spacers etc. Then tube sheet cutting method was applicable.

\section{DOCUMENTS REQUIRED FOR RETUBING}

Once job or po was confirmed, it's compulsory to go through assembly drawing, tube bundle drawing, nozzle detail drawing, name plate drawing are required to submit the below quality/inspection related documents.

- Method statement (Repair procedure)

- Inspection Test plan(ITP)

- Welding Procedure Specification \&Procedure Qualification Record(PQR)

(WPS)

- Welder Qualification Test Record (WQTR)

- Tube Expansion Procedure(TEP)

- NDT Procedures

- Hydro Test Procedures \& Pneumatic Test Procedures

From the drawing resulting details tube like expansion ratio, expansion dimensions, NDT requirements, hydro test pressure details, method of expansion, welding details was identified and tools arranged accordingly. Tube to tubesheet welding qualification and its material needs will be identified and arranged accordingly.

\section{HEAT EXCHANGER RETUBING BY TUBESHEET CUTTING METHOD}

Following steps involved in Heat Exchanger retubing by tubesheet cutting method

1. Identify the Equipment by verification of name plate and drawings provided by end user and prepare receiving inspection report.
2. Visual inspection of equipment shall be carried out prior to re-tubing. Dimensional check shall be done during inspection (i.e. overall length of the equipment).

3. New materials shall be inspected and MTC shall be reviewed prior to use.

4. Remove the channel cover and its end flange on both sides (Blinding)and Carry out visual inspection and record areas of damage, corrosion effects on the tube sheet surface, gasket areas, and any other affected areas.

5. Cut and remove old Plugs (If available) and remove the weld metal where required for welded tubes using standard cutters and clean the hole.

6. Perform the sweep blasting on both corroded Tube sheet faces before tube removal. Take precaution on Gasket surface area.

7. Remove the existing weld metal using tube facer / bevelling tool and Cut all the tubes at Floating side tube sheet with the correct specification of cutting tools (i.e. internal tube cutter).

8. Cut the shell to tube sheet weld joint on Fixed side tube sheet hard stamped tube sheet orientation prior to cutting (Refer Figure 1). Dimensional inspection (tube sheet to tube sheet length in prior to cutting the tube sheet). If any dispensary found against drawing, inform to end user.

9. Perform cleaning of shell internals after pulling out bundle and carryout sweep blasting on bundle skeleton. The internal visual inspection report after cutting the tube sheet (with photographs) shall be supplied to end user for review and record. UT thickness measurement record for shell after cleaning (sweep blasting or hydro jetting) as applicable.

10. Re-groove or reaming of Tube sheet/s holes of required. Bevel the External tube sheet holes and clean the tube sheet holes ensure that dirt or foreign material are not present.

11. Perform $100 \%$ Dye Penetrant Testing on tube sheet holes after machining contour radius(R3).

12. Assemble the tube bundle skeleton with new tie rods/spacers (if required) and tubes. Visual inspection and dimensional inspection of tube sheet/s holes. Record tube sheet/s hole diameter to determine tube wall thinning (10\% tube quantity)

13. Machining and inspection of both top and bottom tube sheet contour radius (R3) for carrying out strength weld.

14. Insert New Tubes; new tubes to be inserted must be clean and free from oil and dirt. Extra care shall be observed during tube insertion to avoid tube and tube sheet damage.

15. Assembly, Fit-up and welding of tubesheet/s to shell. Welding to be done as per approved WPS and qualified welder.

16. Perform $100 \% \mathrm{PT}$ on shell to tubesheet joint/s after root pass and final weld completion. Perform UT on shell to tubesheet joint/s after final weld 
completion where applicable, Use MT if UT is not possible.

17. Dimensional inspection to ensure the tube sheet to tube sheet length (as same as before cutting). Set the tube projection as per drawing.

18. Weld first pass on tube to tube sheet joints as per approved WPS and qualified welder.

19. Perform $100 \%$ Dye Penetrant Testing after completion of 1 st pass welding.

20. Weld second pass tube to tube sheet joints as per approved WPS and qualified welder.

21. Perform $100 \%$ Dye Penetrant Testing followed after completion of 2 nd pass welding.

22. Carry out tube expansion after completing of tube to tubesheet welding activities.

23. Percent of tube wall thinning for light expansion shall from $1 \%$ to $3 \%$ and verified by three point bore gauge (\% may vary according to plant standard). Refer Figure 2
24. Air leakage test (Pneumatic test) for tube-to-tube sheet joint after expansion with soap air at 0.35 BarG or design pressure whichever is smaller.

25. Final Visual Inspection after completion of retubing activities.

26. Carryout hydro test on shell side tube side as per required test pressure (Deblinding).

27. Complete draining of water and dried out of the shell and tube side shall be ensured after hydro testing / in prior to N2 purging. Dry-out and Nitrogen purging/blanketing of both tube and shell side @ 5 psig. Welding grade nitrogen (99.9\% pure) shall be introduced. Purging would have to repeat for several times to get the purest N2.

28. All Inspection points shall be as per approved Inspection and Test Plan (ITP) All Inspection points shall be as per approved Inspection and Test Plan (ITP)

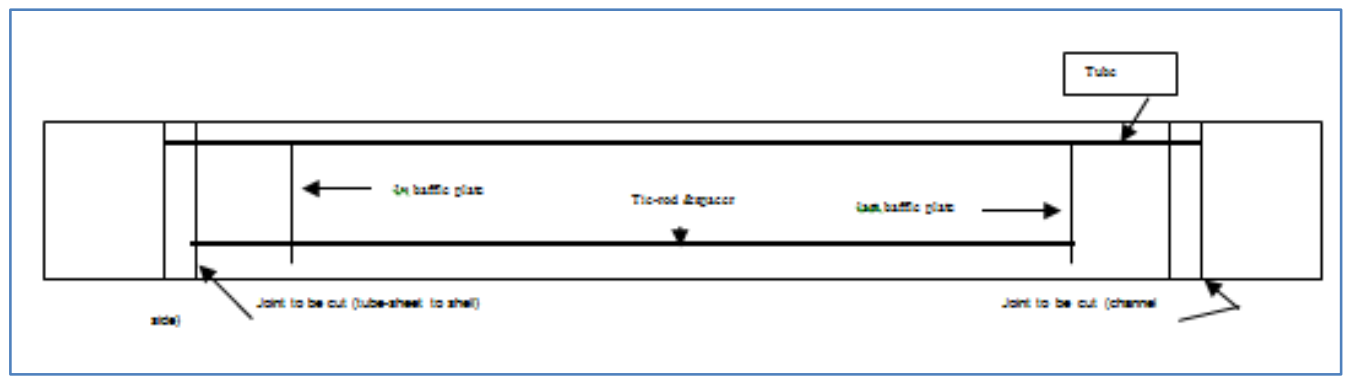

Fig-1: Tubesheet Cutting

\section{HEAT EXCHANGER RETUBING BY WITHOUT TUBESHEET CUTTING METHOD}

The main difference between both the method was time duration and internal inspection. If we did not cut the tubesheet means we can't inspect the internals of heat exchanger like baffles, tie rods, spacers etc. and also time duration will be reduced $50 \%$ less than tubesheet cutting method.

Following steps involved in Heat Exchanger retubing by without tubesheet cutting method

1. Identify the Equipment by verification of nameplate and drawings provided by end user and prepare receiving inspection report.

2. Visual inspection of equipment shall be carried out prior to re-tubing. Dimensional check shall be done during inspection (i.e. overall length of the equipment).

3. New materials shall be inspected and MTC shall be reviewed prior to use.

4. Remove the channel cover and its end flange on both sides (Blinding) and Carry out visual inspection and record areas of damage, corrosion effects on the tube sheet surface, gasket areas, and any other affected areas.
5. Cut and remove old Plugs (If available) and remove the weld metal where required for welded tubes using standard cutters and clean the hole.

6. Perform the sweep blasting on both corroded Tube sheet faces before tube removal. Take precaution on Gasket surface area.

7. Remove the existing weld metal using tube facer / bevelling tool and Cut all the tubes at Floating side tubesheet with the correct specification of cutting tools (i.e. internal tube cutter).

8. Cut the tubes from one end fixed side using tube internal cutter.

9. Pull out the tubes from fixed side by tube pulling ma-chine.

10. Remove the stubs from another end fixed side tube sheet.

11. Re-groove or reaming of Tube sheet/holes of required. Bevel the External tubesheet holes and clean the tube sheet holes ensure that dirt or foreign material are not present

12. Perform $100 \%$ Dye Penetrant Testing on tubesheet holes after machining contour radius (R3).

13. Visual inspection and dimensional inspection of tube sheet/s holes. Record tubesheet/s hole diameter to deter-mine tube wall thinning $(10 \%$ tube quantity) Machining and inspection of both top and bottom tube sheet contour radius (R3) for carrying out strength weld. 
14. Insert New Tubes; new tubes to be inserted must be clean and free from oil and dirt. Extra care shall be observed during tube insertion to avoid tube and tubesheet damage.

15. Set the tube projection as per drawing.

16. Weld first pass on tube-to-tube sheet joints as per approved WPS and qualified welder.

17. Perform $100 \%$ Dye Penetrant Testing after completion of 1 st pass welding.

18. Weld second pass tube-to-tube sheet joints as per approved WPS and qualified welder.

19. Perform $100 \%$ Dye Penetrant Testing followed completion of 2 nd pass welding.

20. Carry out tube expansion after completing of tube to tubesheet welding activities.

21. Percent of tube wall thinning for light expansion shall from $1 \%$ to $3 \%$ and verified by three point bore gauge. (\% may vary according to plant standard). Refer Figure 2

22. Air leakage test (Pneumatic test) for tube-to-tube sheet joint after expansion with soap air at 0.35 BarG or design pressure whichever is smaller.

23. Final Visual Inspection after completion of retubing activities

24. Carryout hydro test on shell side tube side as per required test pressure (Deblinding).

25. Complete draining of water and dried out of the shell and tube side shall be ensured after hydro testing / in-prior to N2 purging. Dry-out and Nitrogen purging / blanketing of both tube and shell side @ 5 psig. Welding grade nitrogen (99.9\% pure) shall be introduced. Purging would have to repeat for several times to get the purest N2.

26. All Inspection points shall be as per approved Inspection and Test Plan (ITP).

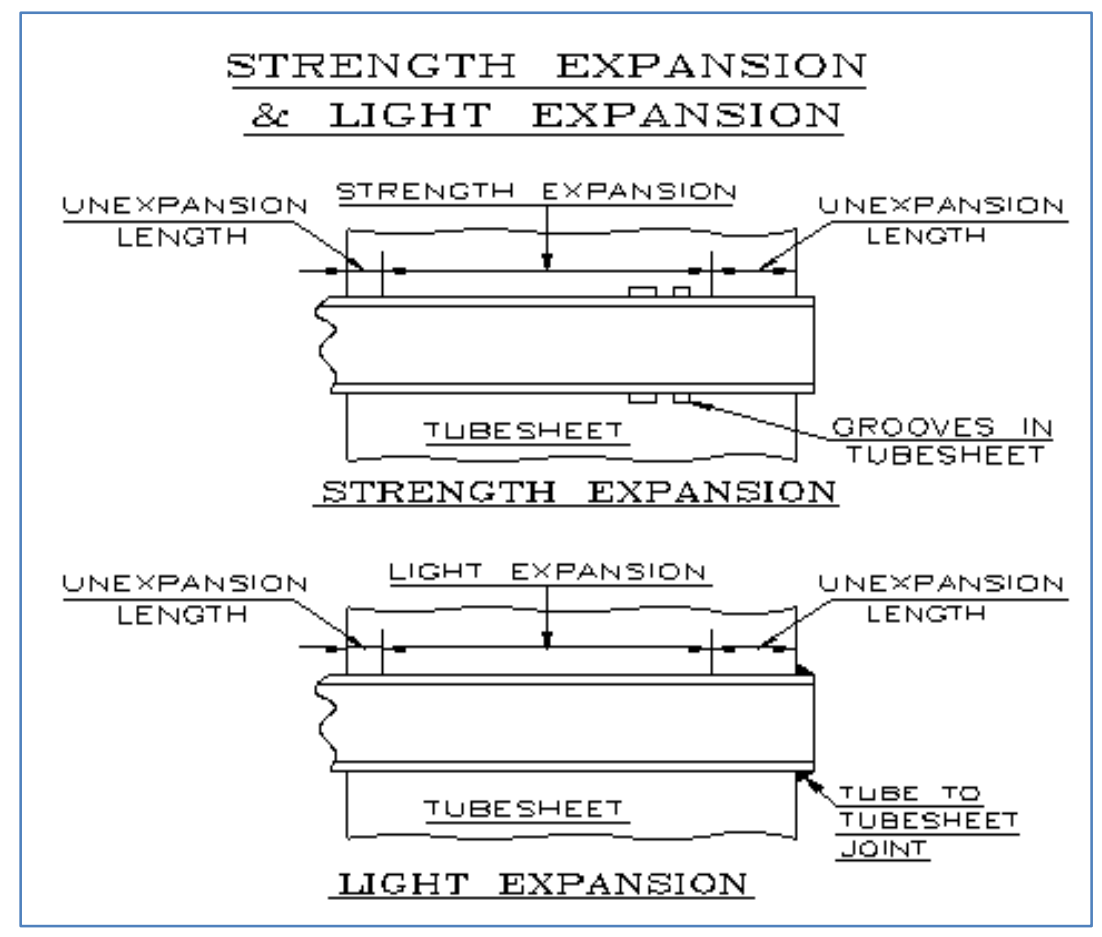

Fig-2: Strength Expansion \& Light Expansion

\section{CONCLUSION}

Based on the existing condition, there is no standardized procedure or steps available in heat exchanger retubing. Procedures may vary according to plant, inspectors, contractors etc. Above procedure was prepared based on study carried out on more than 75 heat exchangers retubing in Aramco \& Sabic affiliates plants. This paper describes standardized procedure for retubing of both methods of heat exchanger, which satisfies all the inspection criteria standards. This procedure was acceptable in Saudi Aramco Plants, SABIC its affiliates plants in kingdom of Saudi Arabia. This standardized procedure can also be modified for heat exchanger retubing which does not require Tube to tubesheet welding. The Practical retubing of heat exchanger for both methods (First method by tube sheet cutting method pull out bundle and second method by without cutting the tube sheet) is systematic and is perfect enough.

\section{REFERENCES}

1. Lebele-Alawa, B. T., \& Egwanwo, V. (2012). Numerical Analysis of the Heat Transfer in Heat Exchangers. International Journal of Applied Science and Technology, 2(4).

2. Master, B. I., Chunangad, K. S., Boxma, A. J., Kral, D., \& Stehlik, P. (2006). Most frequently used heat exchangers from pioneering research to worldwide applications. Heat

Transfer 
3. Yokell, S. (2004). Appropriate correlations for assessing expanded tube-to-tubesheet joint strength. J. Pressure Vessel Technol., 126(3), 376381 .

4. Purandare, P. S., Lele, M. M., \& Gupta, R. K. (2015). Experimental investigation on heat transfer analysis of conical coil heat exchanger with 90 cone angle. Heat and Mass Transfer, 51(3), 373-379.

5. Bouzid, A. H., \& Kazeminia, M. (2015). Effect of reverse yielding on the residual contact stresses of tube-to-tubesheet joints subjected to hydraulic expansion. In ASME 2015 Pressure Vessels and Piping Conference. American Society of Mechanical Engineers Digital Collection.

6. Nagre, G. P., \& Gadekar, A. V. (2014). Design and Thermal Performance Analysis of Shell and Tube Heat Exchanger by Using CFD-A
Review. International Journal of Science and Research (IJSR), 5(2), 953-955.

7. Merah, N., Al-Zayer, A., Shuaib, A., \& Arif, A. (2003). Finite element evaluation of clearance effect on tube-to-tubesheet joint strength. International journal of pressure vessels and piping, 80(12), 879-885.

8. TEMA Standard of the Tubular Exchanger Manufactures Association.

9. ASME Section VIII, Section IX 2017 edition.

10. Sabic Engineering Standards SES, 2015 Edition

11. Saudi Aramco Engineering standards SAES-D008.2017 Edition

12. Indian Standard (IS: 4503-1967): Specification for Shell and Tube Type Heat Exchangers, BIS, 2007, New Delhi

13. National Board Inspection Code NBIC Part III 2015 Edition. 